\title{
Arbor
}

\section{Córdoba en sus portadas civiles}

\author{
Arturo Ramírez Laguna
}

Arbor CLXVI, 654 (Junio 2000), 233-252 pp.

Acordé con mi buen amigo Angel Aroca, director de la Real Academia de Córdoba una colaboración en un numero dedicado a Córdoba en la prestigiosa revista Arbor sobre algún aspecto de la singularidad de esta ciudad y en relación con la arquitectura. Mas tarde, pensando en ello, llevado por el entusiasmo y la inconsciencia le adelanté que versaría sobre las portadas de las casas de Córdoba.

Recuerdo que el arquitecto Ignacio Gárate, autor del fundamental tratado «el arte de la cal», decía en tono simpático que para aprender sobre un tema nada mejor que proponerse hacer un libro. Algo parecido me ha ocurrido con este modesto articulo y es que para saber lo poco que uno sabe sobre un tema solo tiene que proponerse escribir un articulo.

Cuando he buscado alguna bibliografía, y sobre todo, cuando paseándome me he detenido ante las muchas portadas que existen en la ciudad, algunas conocidas superficialmente y otras que me habían pasado desapercibidas, he comprendido que la colección de portadas conservadas en Córdoba forma un patrimonio riquísimo lleno de matices que nos transmite, de manera elocuente, mucho de la historia de la ciudad, de sus gentes y artistas.

Aunque el arte religioso ha despertado mas expectativas en los estudiosos de las artes locales, sea por su refinamiento o por su riqueza, algunos edificios civiles se han incluido entre los reseñables. En los Paseos por Córdoba, de D. Teodomiro Ramírez de Arrellano y Gutiérrez de Salamanca, publicados entre 1.873 y 1.885 se recogen muchas historias relacionadas con las casas solariegas y sus habitantes. Su hijo, D. Rafael, en su Inventario monumental y artístico de la provincia de Córdoba, de 1.904, incluye algunas casas solariegas destacando sus portadas. También Miguel Orti Belmonte y todos los autores de Guías 
de la ciudad. En los primeros escritos mencionados se desprecian los ejemplares «churriguerescos» que tanto detestaron los ilustrados neoclásicos.

Estos datos preexistentes se han completado con aportaciones más profundas de algunos miembros de la cátedra de Historia del Arte de la Universidad de Córdoba, que han sido difundidos fuera de la Facultad en artículos y enciclopedias. También existen algunos raros escritos de Samuel de los Santos en el mejor estilo científico recopilador y por ultimo aportaciones gráficas en proyectos de arquitectos.

Dé la época musulmana no quedan edificios civiles aparte de los que lentamente se desentierran en Medina Azhara pero aunque existieran, es raro que podamos encontrar portadas como tales salvo en las fundaciones reales o en las puertas de las murallas. Los islamocordobeses consideraba la ostentación exterior de sus casas una cosa reprobable según su ley coránica. Salvo en los casos áulicos, las formas artísticas se reservaban para el interior de los patios.

Cuando los cristianos con su rey Fernando III toman la ciudad almohade de Córdoba se reparten su abandonado caserío con largueza, puesto que la ciudad quedó en gran parte abandonada. Es de suponer el gran impacto que la manera de vivir islámica debió producir en los conquistadores norteños y con qué agrado debieron habitar las mejores casas de los vencidos. La vida guerrera obligaría a habilitar torres de defensa pero no creo que hubiese necesidad de construir casas de habitación en tan extenso casco urbano.

El programa de cristianización de la ciudad, convirtiendo las mezquitas en iglesias por las obvias diferencias de culto, debió acaparar todos los esfuerzos constructivos. No sabemos hasta que punto los primeros moradores alteraron las viviendas que encontraron o si simplemente colgaron sus escudos a las puertas de las casas como parecen revelar los detalles de cuelgue de pequeños escudos labrados en piedra en portadas posteriores (Iglesia del monasterio de Santa Clara de Belalcazar etc.).

Tal vez algunas de las portadas más antiguas de la ciudad se demolieron como represalia de Pedro I a los nobles que les fueron hostiles en su conquista de Córdoba.

Las primeras portadas que encontramos pertenecen al siglo XV aunque existan casas atribuibles al siglo XIV. Y constituyen dos series: una con modelos moriscos y otra con patrones góticos.

Los castellanos aunque empapados de las formas islámicas pronto debieron plantearse exhibir su estatus en las puertas de sus casas ya que su filosofía propiciaba un individualismo de exaltación de sus 


\section{Córdoba en sus portadas civiles}

valores guerreros, favores por gestas o antepasados ilustres. Parece que las decoradas yeserias de las puertas de las salas principales que se abren al patio en la casa morisca pueden trasladarse al exterior. Tal es el caso de la portada de la casa de los Cea (Fig.1), hoy conocida como del Indiano. Talladas en piedra local se muestran una serie de lacerías en cadenetas y sebka que tienen que ver con el mudéjar toledano y con el reino granadino. Destaca sobre todo el dintel con dovelas engatilladas que presenta un complejo sistema de lazo con virtuosismo de la labra. Esta labor de engatillado está presente en todas las portadas mudéjares de la ciudad y parece sustituir a la labor de ataurique en los dinteles musulmanes. Su origen puede encontrarse en una de las puertas occidentales de la mezquita de Al-haquen y seguirse en una puertecita alfonsina de la torre del exconvento de Santa Clara.

La casa de los caballeros de la orden de Calatrava que existió antes de la hoy desaparecida fonda Suiza en las Tendillas era otro ejemplar de la serie según los datos que de ella refiere Ramírez de Arellano quien la conoció. Su filigrana debía ser parecida a la de las dovelas de la portada sur de San Miguel que es la fiel replica cristianizada de una entrada de mezquita.

FIGURA 1

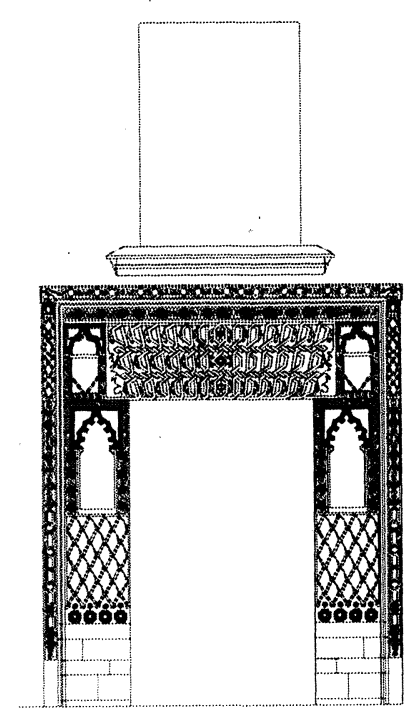

FIGURA 2

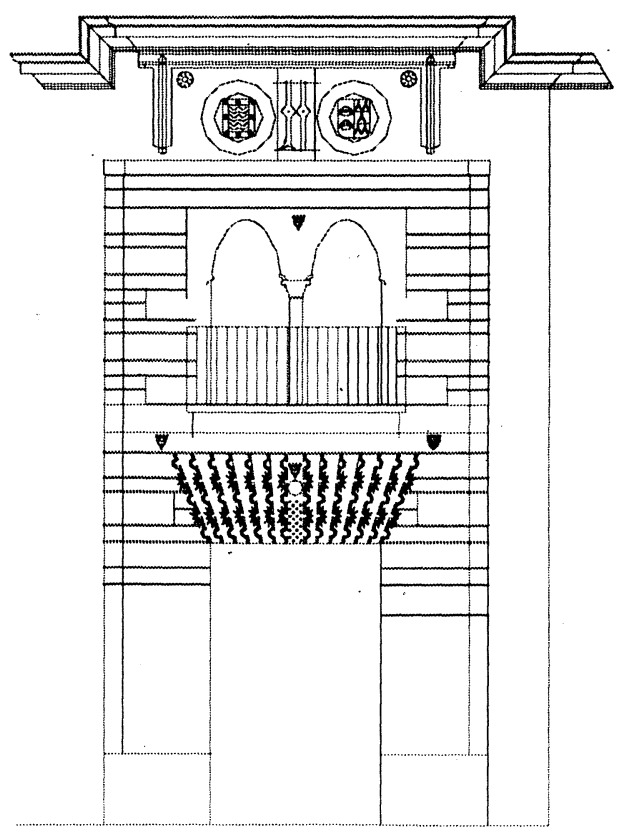


La magnifica portada de la casa de los Aguayos (Fig.2), hoy camuflada su piedra por una pintura al temple, está más próxima a la del palacio de Tordesillas hoy del monasterio de Santa Clara en esa villa. Tiene en las jambas una labor de avitolado en piedra que comparte con la fachada del palacio mudéjar de Sevilla construido por el rey Don Pedro. Aun muestra un aljimez sobre la puerta con arco túmido, que es un atavismo islámico único en esta ciudad. Aparece el engatillado en sus dovelas con una labor de laceria en la clave menuda y complicada como un ataurique. Tiene en cambio los pequeños escudos del apellido en las enjutas y clave como detalle cristiano, $\mathrm{y}$, en este sentido, tiene un remate gótico isabelino donde la familia manifiesta su adhesión al nuevo estilo propiciado por los Reyes Católicos. Esta misma terminación gótica cristianiza la fachada del palacio de los Ceas y la fachada de los marqueses del Carpio.

Parece que el aljimez cae pronto en desuso. Las veleidades moriscas de Pedro I y los Trastámara en la nueva monarquía de Fernando e Isabel no se toleró cuando vióse claro que el reino de Granada estaba condenado a desaparecer. Los Reyes Católicos tratan de imponer un estilo nacional, actitud que seria repetida, en distintas versiones, por sus sucesores.

Existe otra muestra de portada mudéjar con rico engatillado en la plaza de Judá Leví (Fig.3), otra en la portada a calle Cabezas del palacio de los marqueses del Carpio (Fig. 4) con una ventana gótica en planta alta, otras con el engatillado simplemente acusado como acodamiento de las dovelas en una puerta lateral del palacio de Namias (Fig. 5).

Como restos de puertas moriscas hay que mencionar una parte de dintel en una casa de la calle Mucho Trigo y otros restos en una portada de la plaza de Valdelasgranas.

De las portadas de tradición gótica la más antigua es la del alcázar cristiano y más tardías una serie de portaditas civiles construidas durante el siglo XV y principios del XVI en gótico isabelino que poco a poco incorporan elementos renacentistas.

Una de las más puras en el estilo es la pequeña portada de la casa de los Hoces en la calle Sánchez de Feria, en la que seria después casa de los Guzmanes y hoy Archivo Municipal (Fig.6). Los escudos son pequeños y se repiten en la clave y enjutas. El hueco duda entre arco y dintel. En la calle Osio se conserva otra portadita con la mitra y báculo del obispo (Fig. 7). En la misma calle existe otra más con un dintel descargado por un arco trilobulado liso. 
Córdoba en sus portadas civiles

FIGURA 3

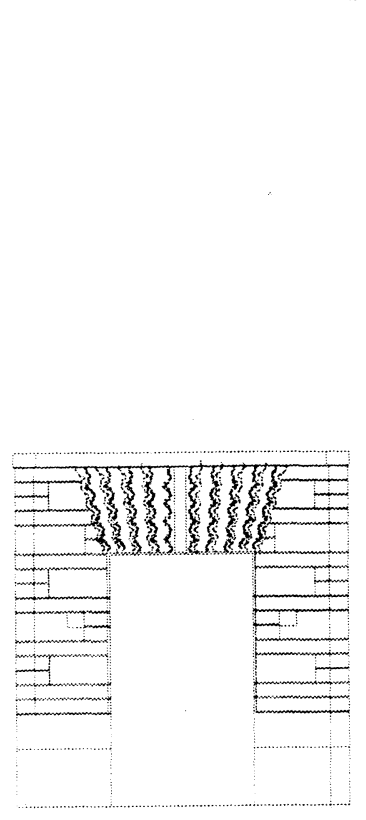

FIGURA 5

FIGURA 6

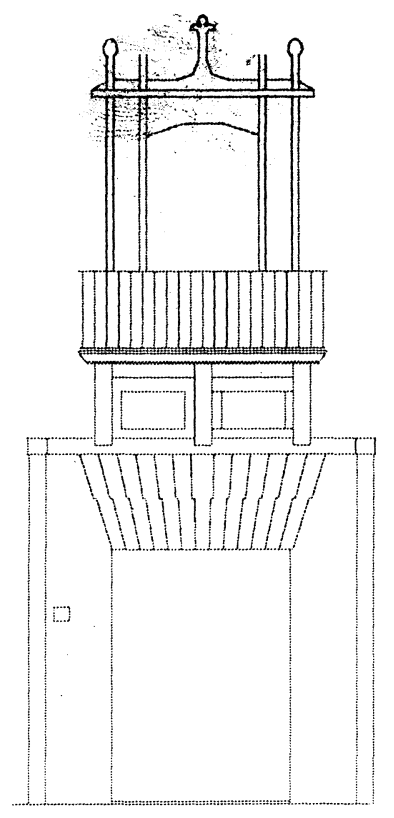

FIGURA 4
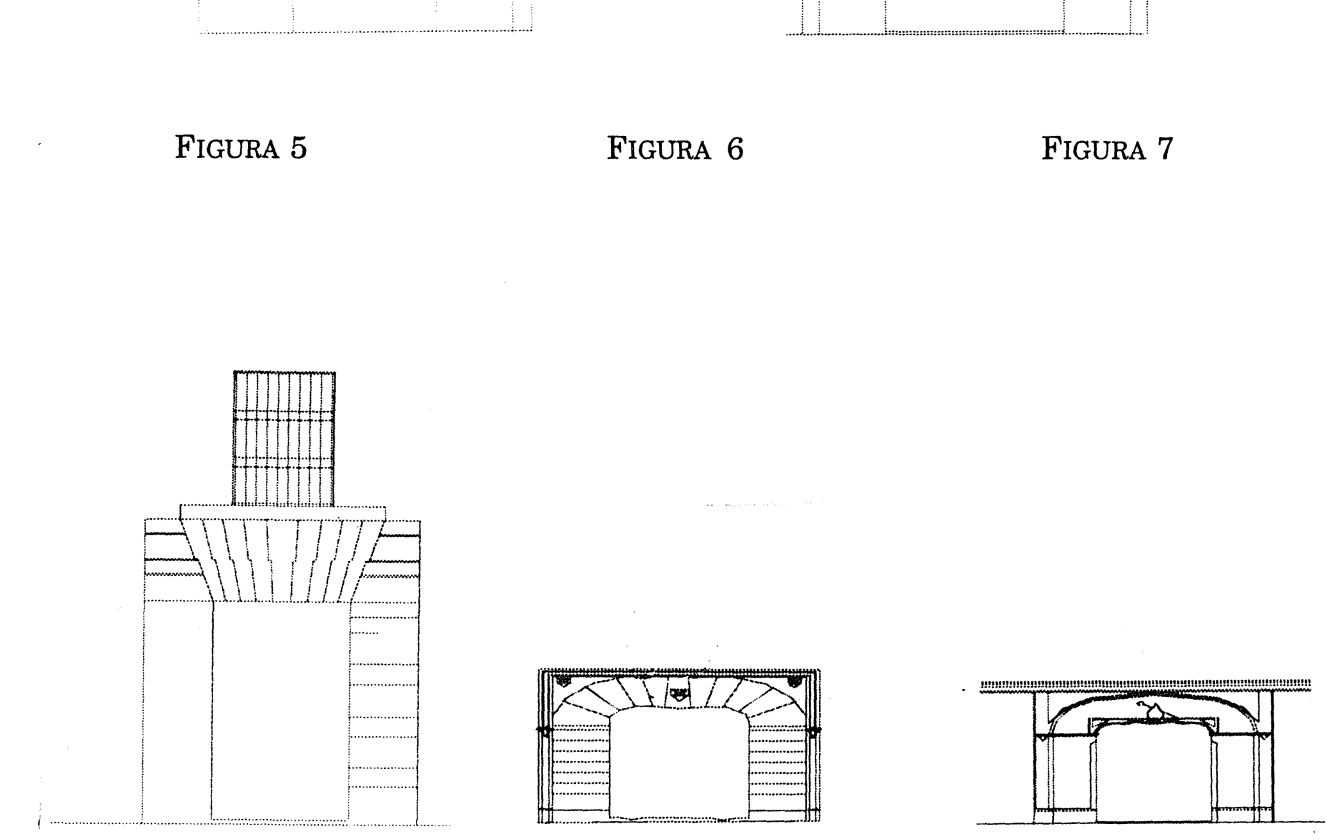
En la plazoleta que hace la calle Medina y Corella se encuentra la sede de la Filmoteca Andaluza, casa que antes estaba ligada al Hospital de San Sebastián, la puerta de entrada al centro es una portadita gótica llena de fantasía. Tiene dos soportes laterales que están formados por el ensamble de dos pilares de planta oblonga, el menor sobrepuesto al mayor, y que se han fundido mediante unas grapas entre ellos. Sobre estos extraños soportes una serie de bolas gallonadas de mayor a menor siguen las pilastras hasta el tejaroz. Parecen inspiradas en un yamur de mezquita y creo que son únicas. Las molduras que recercan el hueco, adintelado con las esquinas redondeadas, se cruzan en la clave formando una especie de lazo. (Fig.8)

Con riqueza de perfilería gótica se encuentra la portada de la casa $\mathrm{n}^{\circ} 9$ de la calle Obispo Fitero (Fig. 9) con arco adintelado y conopio que trasciende el tejaróz. Tiene una moldura cóncava rellena de flores repetidas que es el ultimo eslabón de la cardina empleada en las portadas religiosas. Sus escudos son muy posteriores.

FIGURA 8

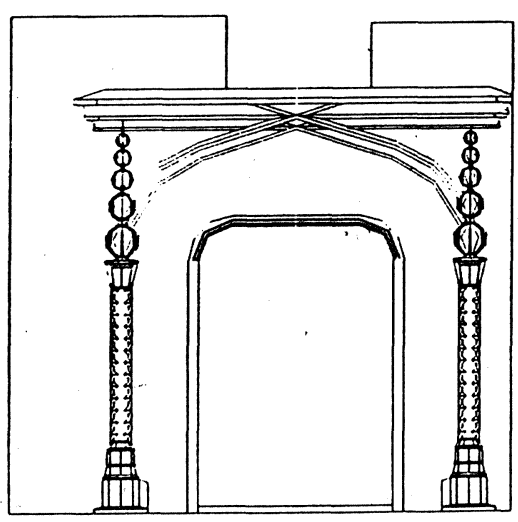

FIGURA 9

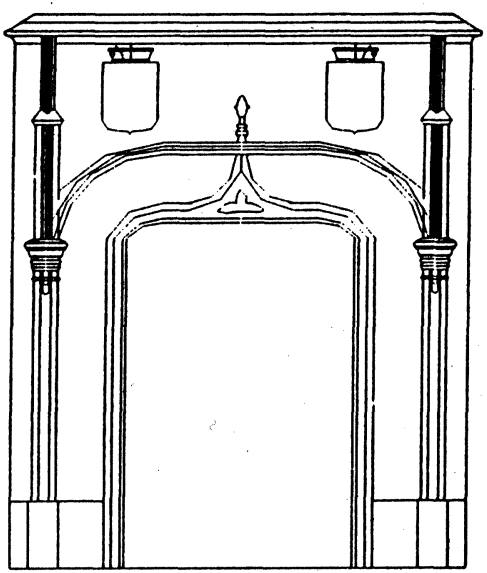

Én el palacio de la Diputación Provincial se conserva sobre la fachada que recae al aparcamiento una buena portada gótica procedente de la calle Albucasis. Estaba situada en lo que hoy es Albergue Juvenil 
en el retranqueo de la calle y en el edificio moderno allí construido se ha reservado una puerta y ventana equivalentes. (Fig. 10). Era de una casa de dos plantas y se labró con ventana superior de marco cuadrado ligada al tejaróz. Este marco, que se repite en todas las posteriores, tiene una curiosa labra repetitiva y de gran efecto que el profesor Chueca Goitia denominó « de galleta» por su parecido con el relieve impreso. Se define por una red ortogonal de baquetones maclados como en celosía que consiguen un efecto de claroscuro muy plástico. Este motivo tuvo una amplia acogida en la ciudad y sus aledaños y se repite con pequeñas variantes. En una casa de la calle Rey Heredia (Fig.11) toda la portada se resuelve con este procedimiento, salvo el detalle clásico de dos ménsulas en las esquinas interiores del marco de la puerta.

La casa que fue de los marqueses de la Vega de Armijo en la calle Agustín Moreno tiene una portada rehecha con ventana superior original. Coexiste el marco "engalletado" de doble urdimbre con frontón superior y relieves humanistas donde figura la fecha de 1.520 incisas en una cartela sobre el dintel.
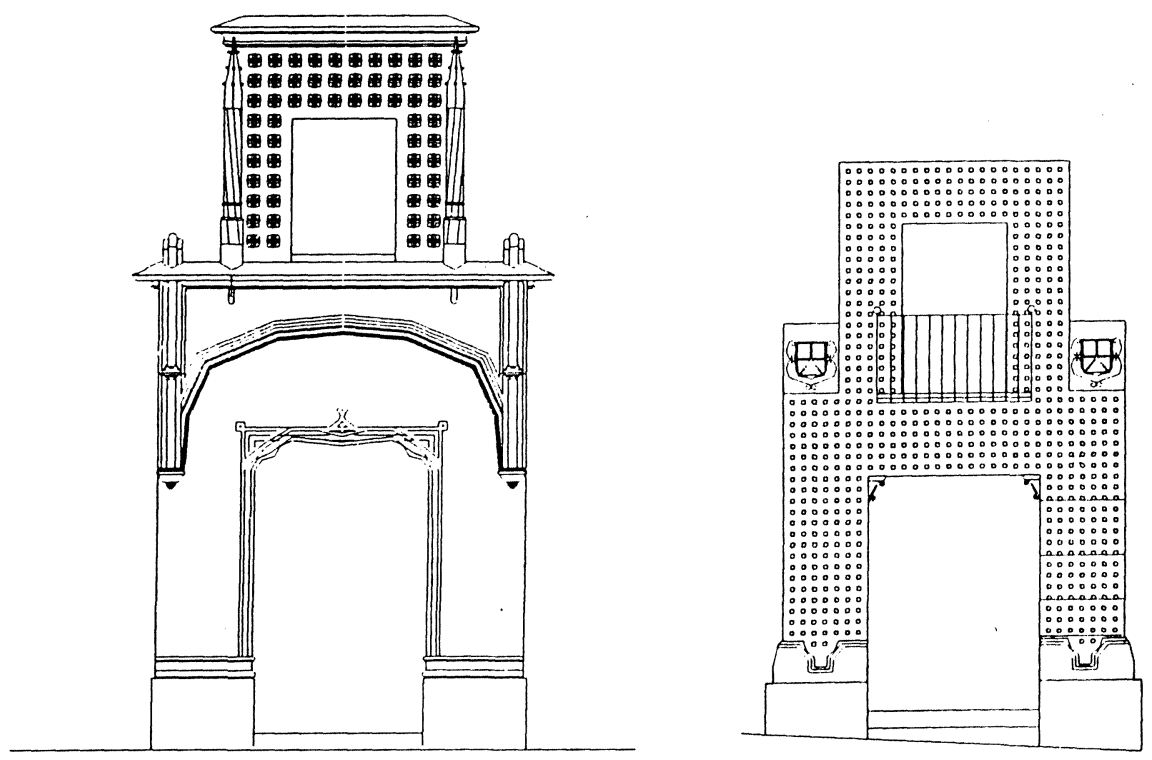
La conquista de Granada supuso la paz definitiva que propició la repoblación y la riqueza en estos reinos. Los extensos caudales que se llevaban las campañas se destinaron a edificaciones piadosas o palaciegas. La Córdoba de aquel entonces era una ciudad ocupada por palacios y monasterios. El obispo, primer noble de la ciudad en cuanto a poder e influencia aprovecha la paz para desarrollar un extenso programa edificatorio renovando las modestas iglesias de la Campiña e incluso definitivamente cristianizando la gran mezquita aljama. Durante este interesante periodo que ocupa todo el siglo XVI, en el que la sociedad se transforma completamente, el gótico se va a sustituir por un nuevo estilo, primero en la decoración que se concreta en el abandono de las labores moriscas del interior de las casas y luego en la arquitectura que poco a poco asume el legado clásico.

La existencia de buenos canteros en Córdoba, estimulados por las obras anteriores se ejemplariza en la familia de los Ruiz que dará maestros mayores a la catedral y al Consejo y protagonizarán el interesante paso de estilo durante todo el siglo con obras destacadas.

El primer maestro Hernan Ruiz, "el viejo", continua el estilo gótico de su padre Gonzalo Rodríguez adaptándose a los nuevos motivos decorativos que le marcan prelados y nobles. Su hijo, que heredará sus cargos, dispone de una formación más completa adquirida a través de otros maestros contemporáneos y por los tratados de los teóricos italianos recién traducidos, lo que le permitió una obra más coherente en el nuevo estilo. El ultimo descendiente de esta familia de arquitectos, Hernán Ruiz III, ejecutó la Puerta del Puente al gusto de Herrera poniendo fin a ese curioso proceso de transformación de estilo y que a partir de entonces se desarrolla como Manierismo.

Del circulo del primer Hernán Ruiz y fechada en 1.540 es la portada de la plaza de San Andrés, de la familia de los Luna, donde se dice que vivió Pérez de Oliva. Es una portada muy plana con la clásica composición de puerta y ventana superior adinteladas. La puerta tiene un marco de entablamento con finas molduras de carretes similar a las portadas romanas. Se adorna con mascarones en la clave del dintel y en los extremos donde se levantan unas pilastras rehundidas. Entre los mascarones unas guirnaldas con cintas de gusto clásico. La ventana también está adornada por pilastrillas rehundidas sobre pedestales y entre ellos a modo de peto se desarrolla una rara labor de carretes próxima al tipo galleta donde se coloca el escudo. (Fig. 12).

Una portada que aun siendo de mediados del siglo XVI arrastra un planteamiento gótico es la que presenta la «casa Chica» del Bailío. Tiene pilastras torsas de baquetones que se prolongan en una especie 

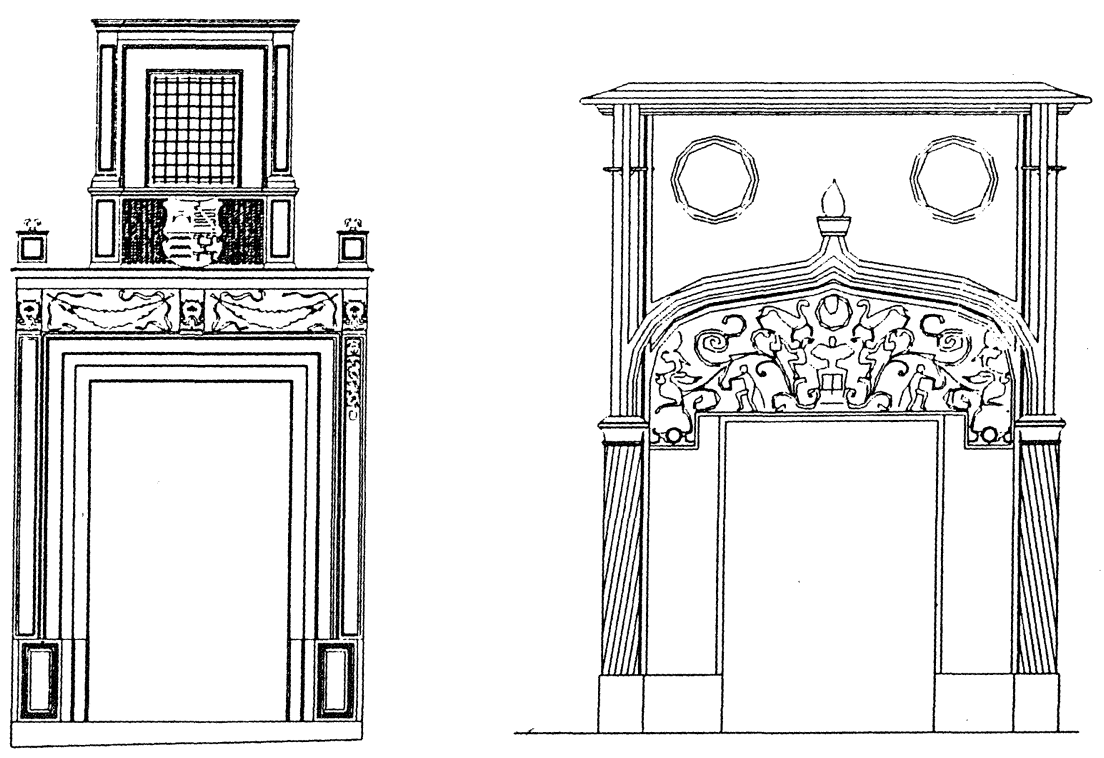

de alfiz con tejaroz. El dintel es recto con un conopio que arrancado de las pilastras que flanquean las jambas y muere a media altura de la portada. El espacio bajo el conopio que sería el dintel contiene en altorrelieve un relleno simétrico de motivos animales y vegetales del mejor gusto italiano. Sobre el conopio y ambos lados, tondos vacíos (Fig.13).

Ejemplo de esta hibridación de estilos se da en la portada de la casa de marqués de la Fuensanta del Valle, hoy conservatorio de Música, fechada en 1.551. En planta baja el hueco está recercado por un marco de tipo galleta que soporta un friso de alegoría mitológica con los dos escudos inscritos en laureas clásicas en los extremos. El relieve está protegido por un tejaroz gótico que une las dos pilastrillas con pináculos que flanquean el marco. En la planta alta se abre una ventana rectangular adornada por un pórtico dístilo del mejor plateresco con una peineta avenerada a modo de frontón.(Fig. 14).

Un ejemplo sobresaliente en la incorporación de lo clásico lo constituye la portada de la casa de los Orive, también conocida como de los Villalones, hoy propiedad municipal tras la compra a la familia Courtois que rescató la casa. Está atribuida a Hernán Ruiz II y fechada en 1.560. La composición equilibrada fué elogiada por D. Fernando Chueca Goitia como la mejor resuelta de todo el renacimiento cordobés. 


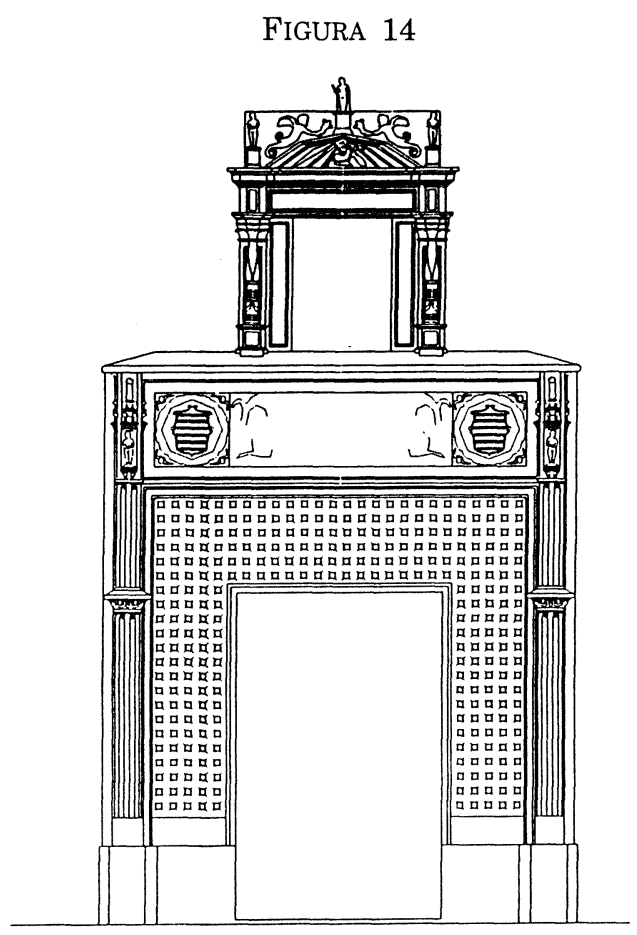

Solo quiero insistir en el detalle del lema virtuoso sobre el dintel que enlaza con las alegorías y en la creatividad del artista en la decoración de la ventana donde se mezclan elementos clásicos con mucha soltura y heterodoxia consiguiendo un efecto rico lejos del plateresco.

La portada que renuncia del gótico es la del palacio de los Paez de Castillejo, hoy Museo Arqueológico. Está atribuida a Hernán Ruiz II y fechada en 1.540 siendo una de las primeras obras de este gran arquitecto. Se plantea como un arco de triunfo de arquitectura ortodoxa donde se alojan una serie de figuras y relieves de ambiente mitológico y heroico con la intención de ensalzar las virtudes y orígenes guerreros de la familia.

Entre 1.572-77 se construye la puerta del Puente, renovando la anterior musulmana que no debió gustarle al rey Felipe II en su visita a Córdoba. La obra la ejecutó Hernán Ruiz III siguiendo las directrices de Herrera fiel interprete de la arquitectura del emperador. Aunque debe mucho al planteamiento de la fachada de los Paez, es más fría en el uso de los ordenes, al modo de Viñola, e inaugura una nueva concepción del estilo que siempre se mantendrá severo bajo los Austrias.

A fines de siglo se establece el uso del carruaje como modo de transporte sustituyendo a la silla sobre caballo. En el estrecho callejero 
de la ciudad esta practica es imposible y se opta por retranquear las fachadas, abrir plazas delanteras y otros recursos, como la puerta en esquina del palacio de Viana. También la preocupación por la perspectiva afecta a toda la fachada que se regulariza destacándose de la trama urbana informe, proceso que afectará a toda la ciudad con el nuevo urbanismo que se desarrollará extensamente en el Barroco.

Juan de Ochoa sucede a Hernán Ruiz III como maestro de la catedral y es el representante del manierismo del final del quinientos. A él se le atribuyen la portada de la Cárcel y Audiencia de Córdoba, la portada del palacio de Viana, la de los Venegas y otras.

La portada de Viana se abre en un chaflán de esquina para tener mejor perspectiva en una pequeña plaza. Tiene el hueco de entrada un marco con despiece de sillería almohadillada y un dintel con fuerte dovelaje. Sobre unos pedestales detrás de las alas del frontón partido, presenta unos tenantes con escudos de armas apoyados sobre leones. En el cuerpo alto tiene balcón y sobre el un escudo más tardío y decorado culmina la portada. (Fig. 15)

Algo mas evolucionada es la doble portada de la casa de los Venegas de Menestrosa, hoy Gobierno Militar sito en la plaza de Emilio Luque. El balcón se soporta sobre unas ménsulas con cabezas de león muy aparatosas. Las alas de la cornisa del frontón partido se continúan y unen por el frente del balcón. Sobre el hueco alto una peineta pesada aloja el escudo principal.

También presenta doble portada la casa $n^{0} 1$ de la calle Realejo. Son grandes huecos con dovelaje marcado y adorno en clave. En este caso la sencillez de las puertas se ve compensado con el adorno superior de las ventanas que en planta baja flanquean los huecos. (Fig. 16)

En la calle Morales $\mathrm{n}^{\circ} 2$ existe una portada de principios del XVII dibujada con más soltura y alegría. Emplea columnas de "orden rústico", elementos muy apreciados en las villas suburbanas del manierismo italiano y que en Córdoba parece raro. Francisco del Castillo empleó este estilo en obras de Granada y en Priego de Córdoba. (Fig. 17)

De 1.624 es la fachada del palacio del Obispo en la calle Torrijos. Tiene balcón sobre ménsulas entre las alas de un frontón partido donde se apoyan dos escudos iguales del obispo Mardones. El hueco superior esta flanqueado por dos pilastras con ancones de gusto manierista que soportan un entablamento con friso abombado decorado con hojas y un frontón recto.

De 1.636 es la portada del antiguo palacio del duque de Medina Sidonia, hoy casa de los Namias, en la calle Rey Heredia. Tiene un cuerpo bajo con ordenación moderada de elementos donde destacan 

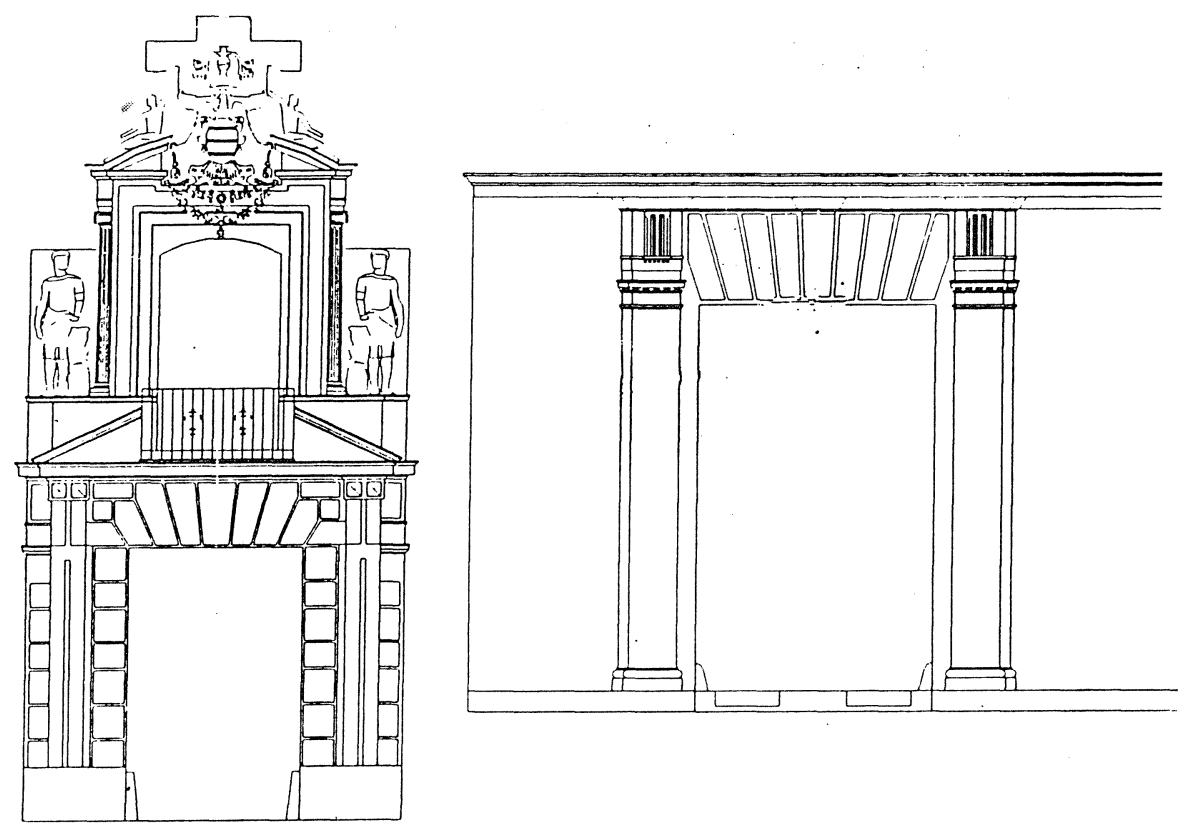

tres ménsulas muy potentes decoradas con mascarones que sujetan una cornisa fina con frontón roto que alberga el balcón. Las alas se ven coronadas por unos remates de bolas herrerianos. El cuerpo superior de marco acodado soporta un frontón curvo donde se aloja un escudo empenachado. (Fig. 18)

Muy próxima a la anterior en el estilo es la portada de una de las casas finales de la calle Alfonso XII que contiene un bloque de viviendas en su interior. La complejidad y riqueza de elementos así como los rizados terminales de sus frontones rotos le dan un aspecto de abundancia y movimiento notables (Fig. 19).

De 1.648 es la portada de la casa de los Fernández de Mesa, hoy conservatorio de Danza, también conocida como palacio de las Quemadas. Es una buena continuación de la Puerta del Puente. El realce de la portada sobre la fachada es impresionante y lo permite el retranqueo de la misma desde la calle creando una plaza que le presta perspectiva (Fig.20).

El siglo XVII fue un siglo de recesión económica y a su mitad se sucedieron una serie de catástrofes que hundieron a la población en la tristeza con el único consuelo de la religión. A mediados del siglo vivían en Córdoba treinta títulos de alta nobleza (un duque, dieciséis marqueses, once condes y dos vizcondes) cincuenta caballeros de ordenes 
FIGURA 17

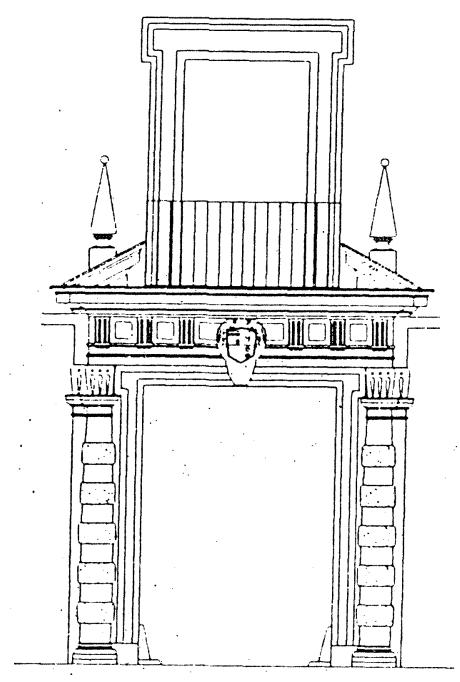

FIGURA 19

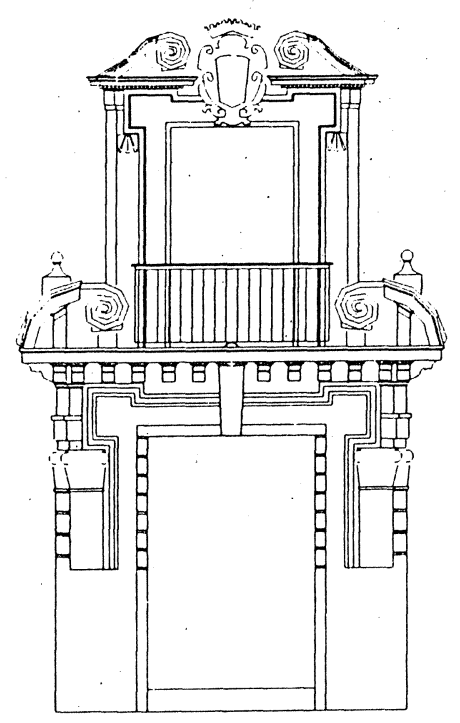

FiguRA 18

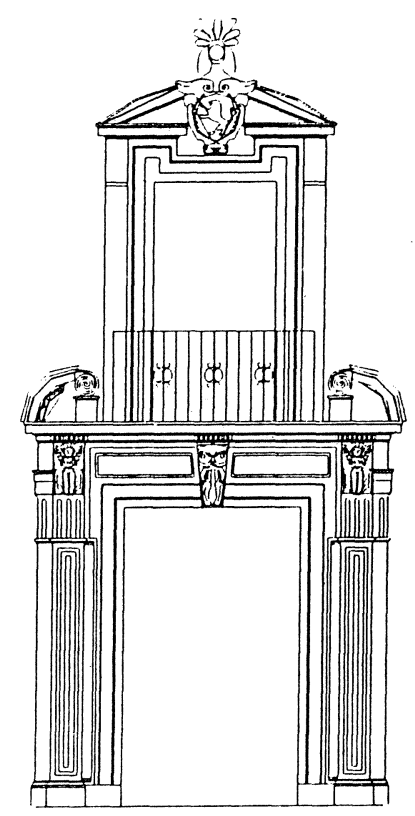

FIGURA 20

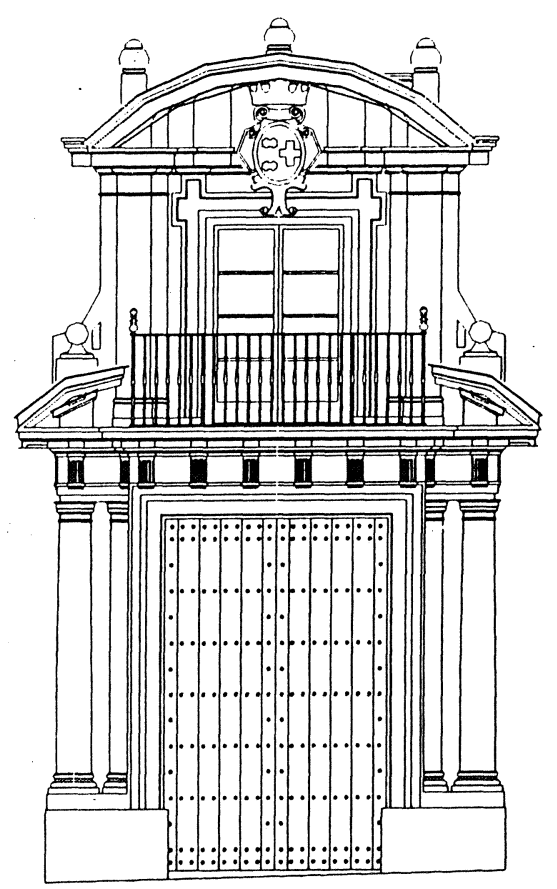


militares y cien hijosdalgos notorios o simples. Es presumible que todas las casas de habitación de esta aristocracia tuviesen portadas con sus escudos a pesar de que muchas hayan desaparecido.

A fines del siglo XVII se mejora la situación económica que se consolida durante el siglo XVIII con la regeneración de los Borbones. Con ellos llegan nuevas maneras a la corte y mucha de la aristocracia local emigra a ella.

En estos dos siglos se impone el balcón frente a la antigua ventana sobre la puerta y esto parece consecuencia de la abundancia de procesiones y de actos callejeros que constituían un espectáculo digno de ser contemplado por varios miembros de la familia, a la vez que eran contemplados los aristocráticos personajes desde la calle.

Una obra singular es la que promueve el cardenal Salazar para hospital junto a la ermita de San Bartolomé y que hoy contiene a la Facultad de Letras de la Universidad de Córdoba. Las trazas se suponen de Francisco Hurtado Izquierdo aunque la ejecución la realizó Juan Camacho. Aunque el edificio se inició en 1.704 la portada se terminaría después.

La portada es de piedra negra de Córdoba con el marco adelantado sobre las parejas de columna y pilastra robada que lo flanquean, el entablamento es toscano con cornisa mensulada. Esta portada se inspira en la de los Fernández de Mesa pero, para mi gusto, la supera. En el cuerpo superior el balcón se adorna con marco apilastrado y un entablamento que se curva en el centro como un dosel para proteger el escudo del prelado cuyas borlas metálicas flotan en el espacio (Fig. 21).

De 1.712 es la portada de la casa $n^{\circ} 4$ de la antigua calle de la Banda hoy calle Jesús del Calvario, muy cerca de la iglesia de San Lorenzo. Es una graciosa portada en ladrillo con elementos aplantillados y clave decorada en el dintel que aun conserva ventana superior enrejada (Fig. 22).

En 1.730 se construye la portada del patio de San Hipólito, dentro del programa de terminación del templo funerario que contiene el sepulcro de dos reyes españoles y que había quedado inconcluso desde el medievo. Esta obra parece estar ligada al circulo de Hurtado y constituye un ejemplo del mejor barroco andaluz. Las curvas mixtilineas del marco cabalgan sobre el dintel anulándolo como elemento y la portada se adorna con orejetas de base y otra serie de recursos que enfatizan la presencia en la cumbre del escudo real. (Fig. 23).

No menos interés presenta la portadita de entrada a la residencia de los religiosos. 
FIGURA 21

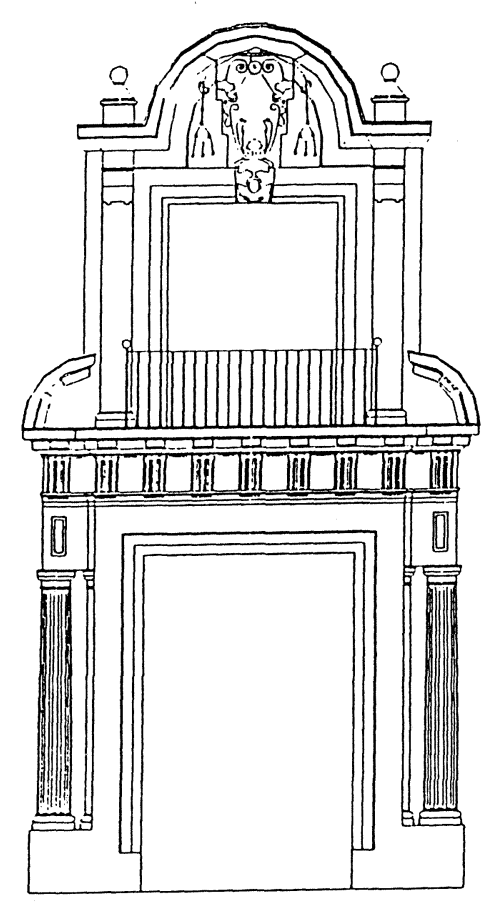

FIGURA 22

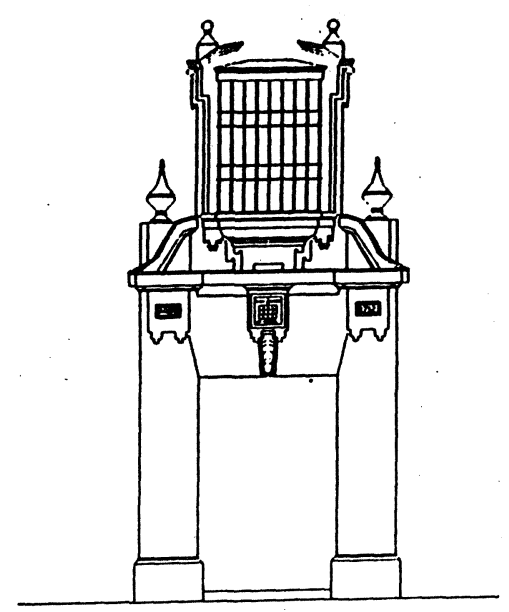

FIGURA 23

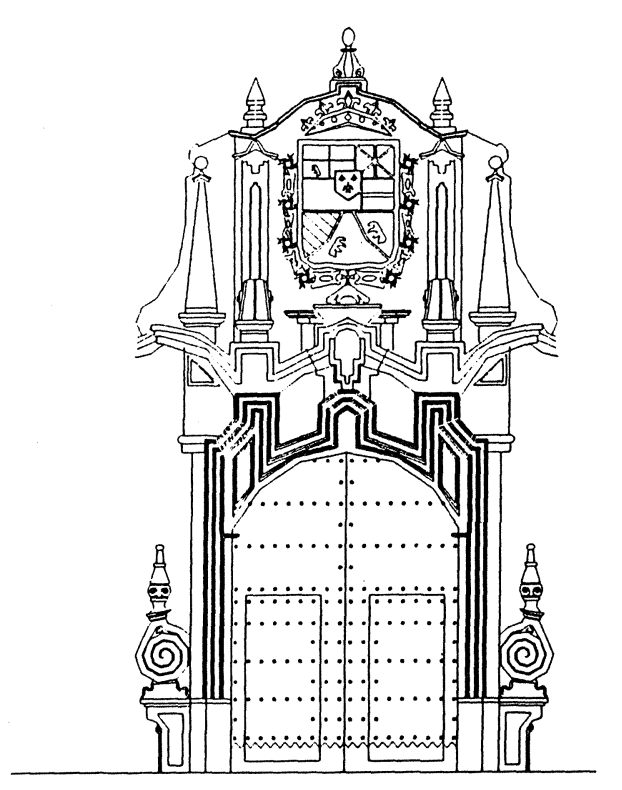


Otras portadas barrocas del siglo XVIII son las que se presentan en el dibujo: la Fig. 24 corresponde a una casa en la calle Cabezas, la Fig. 25 a la casa de los Alvear en la calle Manrique, la 26 a una casa en la calle Tejón y Marín $\mathrm{n}^{0} 22$, y la Fig. 27 a la entrada de carruajes de la Casa del Bailío en la calle Ramírez de las Casas Deza, con una composición puramente geométrica del llamado «barroco de placas».

FIGURA 24

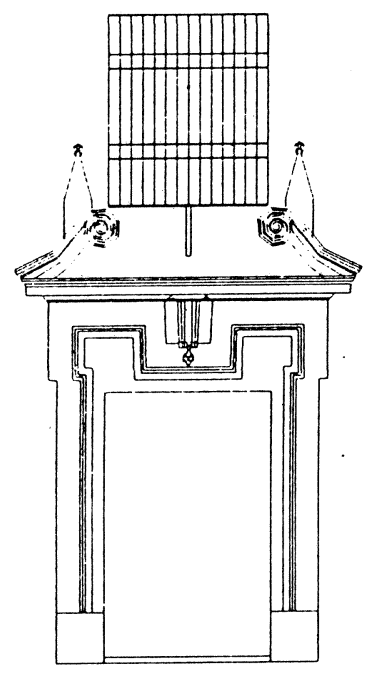

FIGURA 25

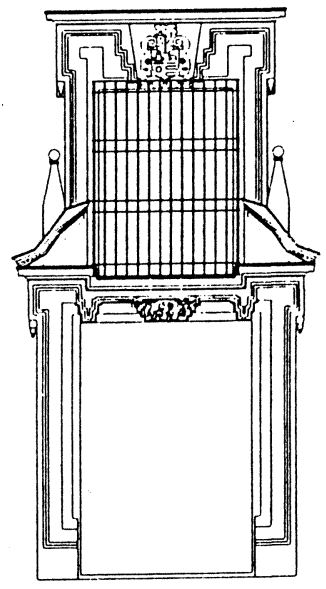

De 1.766 es la portada del palacio del vizconde Miranda, hoy contenedor de viviendas económicas. Es la portada civil con más proporciones de las construidas en la ciudad y en ella se mezclan las distintas clases de piedras ricas usadas en Córdoba: blanca de Luque, negra de la sierra de Córdoba próxima a la ciudad y roja de Cabra. (Fig. 28).

En 1.752 se crea la Academia de Bellas Artes de San Fernando que se constituye en el organismo oficial del buen gusto en la arquitectura y que pone fin al sistema de maestros mayores del Consejo y freno al barroco popular. La mayoría de las fachadas posteriores acusan estas directrices aunque persiste el gusto por el ornato para escándalo de los ilustrados. A pesar de ello se encuentran pequeñas portaditas con la gracia de un barroco moderado. 


\section{Córdoba en sus portadas civiles}

Figura 26

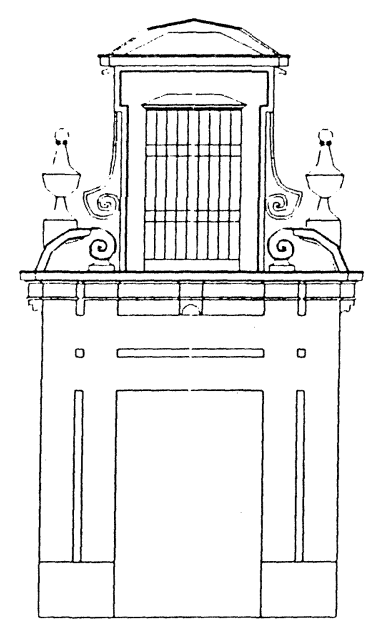

FIGURA 27

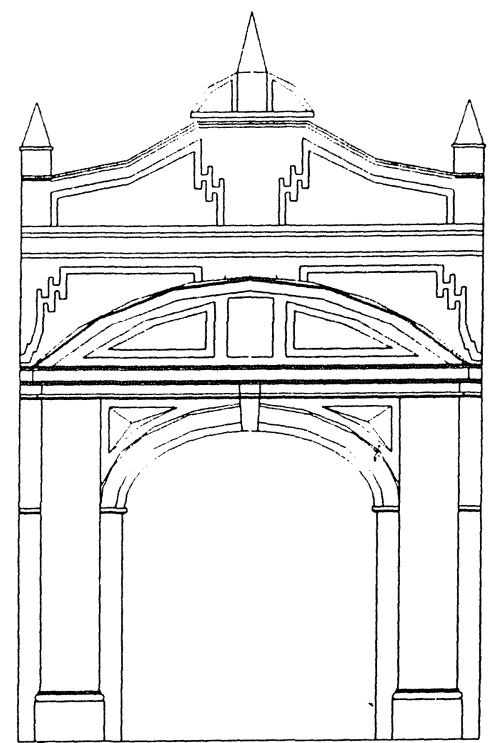

FIGURA 28

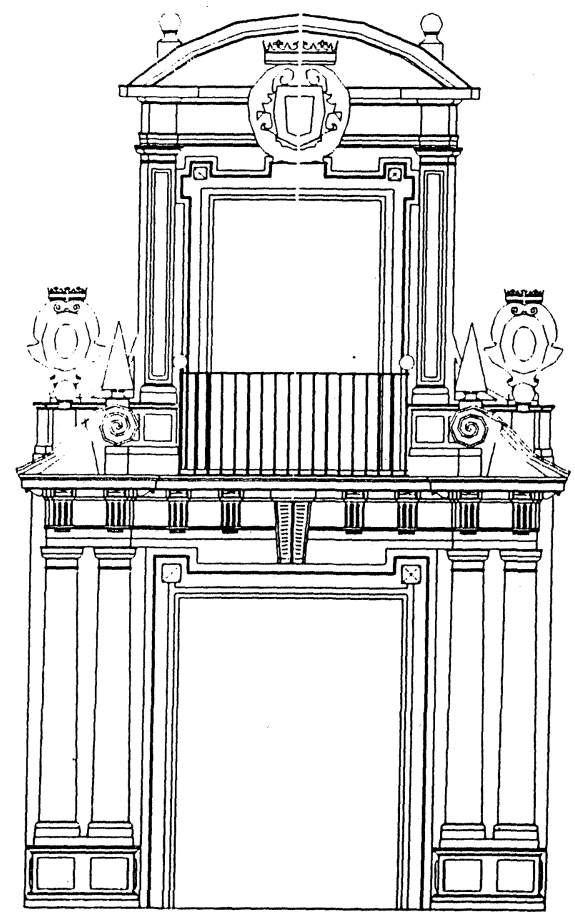


De 1.795 es la portada de la casa solariega de los Muñices que hoy contiene un centro de enseñanza en la calle de este mismo nombre. Esta portada de severidad neoclásica sustituyó a otra renacentista de medallones en piedra arenisca cuyos restos aun se conservan en el portal.(Fig. 29)

FIGURA 29

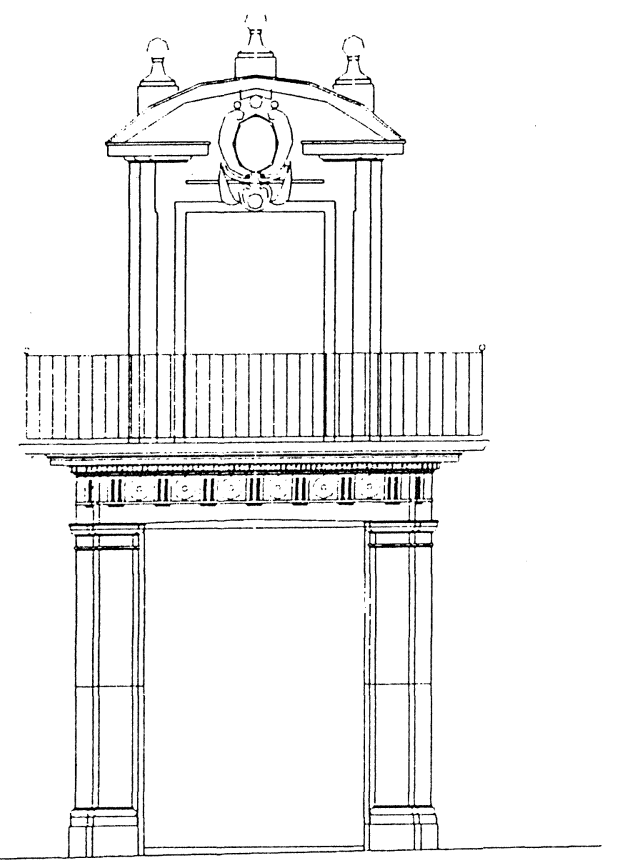

FiguRA 30

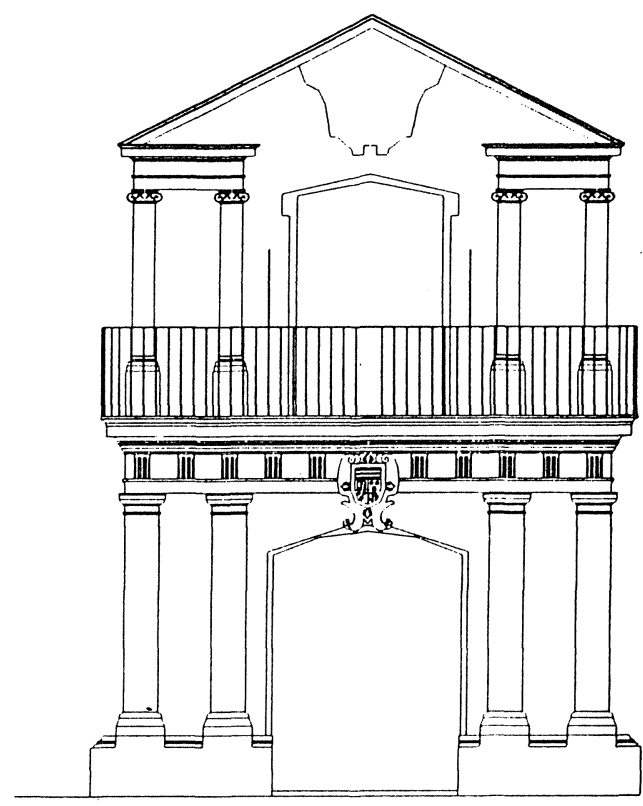

Caso interesante de portada de gusto neoclásico y a la vez recuerdo de los palacios romanos es la que presenta el Colegio de Santa Victoria en su entrada a la residencia y que se atribuye al arquitecto francés Baltasar Debreton.

De esta misma serie es la portada de la casa de los marqueses del Boil, secuestrada en un entrante de la calle Gondomar, que presenta un orden neoclásico animado por la pujanza del dintel.

Existen varias portadas del cambio de siglo, con dintel curvado o recto adornando fachadas de casas medianas en Córdoba, unas disponen de un sencillo friso de triglifos con tondos en las metopas que llega a imponerse como un canon y otras guirnaldas de gusto imperial. Algunas de ellas se alegran con el abombado del dintel, como la $\mathrm{n}^{\circ}$ 8 de la calle Tomás Conde. (Fig. 30). 
En todas las épocas han existido portadas tan sencillas que es imposible catalogarlas por el estilo y que pueden ser del siglo XVI, XVII o XVIII las de piedra y las de ladrillo del XVIII o posteriores. Están formadas por un marco levemente realzado sobre la fachada blanca con un trozo de cornisa superior. Su belleza es la proporción del hueco y el equilibrio con la anchura de su jamba. Algunas se adornan con una clave decorada y otras basan su belleza en la proporción del hueco y su relación con el ancho de la jamba. Estas portadas sobrias le prestan a Córdoba esa austeridad minimalista tan característica. Una de ellas es la sita en calle Cabezas, hoy Archivo de Protocolos. (Fig.31)

FIGURA 31

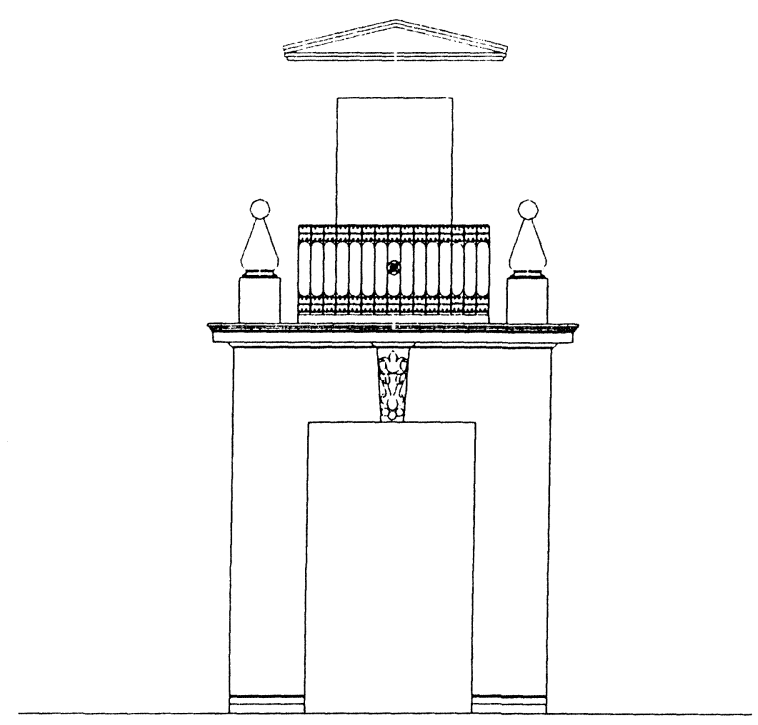

El sentido de la portada muere con el antiguo régimen a pesar de que todas las corrientes historicistas tratan de resucitarla en un intento de enfatizar la importancia de los edificios. Abundan ejemplos durante todo el siglo XIX y principios del XX, con reposiciones de todos los estilos. Se reutiliza una portada tardobarroca en el Seminario de San Pelagio, junto a la Mezquita, se fabrica una portada neogótica en el museo de Bellas Artes de «El Potro», Se abusa del barroco de 
placas en el edificio de uso municipal en el Paseo del Gran Capitán, etc. Cuanto más tardías más anacrónicas parecen.

Los edificios modernos desde el XIX olvidaron las portadas en beneficio de toda la fachada, desconcentrando la arquitectura del edificio de ese elemento. La casa cedió su importancia a los edificios de las Instituciones que se diseñaron con un criterio más unitario. Hoy día, las viviendas se construyen en bloques de pisos y sus puertas no representan a nadie en particular. Los modelos de vivienda aislada no se estructuran en calles y su volumen es más representativo que cualquier elemento aislado. Las pocas casas que se sustituyen en el casco urbano han renunciado una gran parte al uso de este atavismo. 